\title{
The Age of Miracles
}

By Karen Thomas Walke

Published by Random House, 2012, 269 pages (Kindle edition)

Reviewed by:

Jessica Hale (jhale15@wccnet.edu), Professional Services Faculty, Academic and Career Skills Department, Washtenaw Community College

The Age of Miracles: A Novel is Karen Thomas Walker's debut work. In this work, Walker, a graduate of both UCLA and Columbia's MFA program, tells a beautifully crafted apocalyptic story from the perspective of an adolescent named Julia. "The slowing," is the name of the apocalyptic event and a reference to its cause: the continual slowing of the earth's rotation fundamentally changes life on earth, leaving nothing untouched. The length of the day fluctuates; weather patterns shift, becoming extreme and erratic; gravity changes; the magnetic field that shields the earth from the sun's radiation is stripped away, leaving all life vulnerable to toxic radiation; and people and animals begin to develop mysterious sicknesses. Amidst these increasingly perilous conditions, Walker is able to explore complex ideas about relationships, the role of the government, social stratification, love, and what it means to be human, even in the end of days.

This book is organized into 34 chapters, arranged chronologically, beginning with Julia's first recollections of "the slowing" and ending, years later, after her 23rd birthday. The early chapters (14) depict a world in disbelief.

There was no footage shown on television, no burning buildings, or broken bridges, no twisted metal or scorched earth, no house sliding off slabs. No one was wounded. No one was dead. It was, at the beginning, a quite invisible catastrophe. (p. 11-12)

People turn to both science and religion for answers. Julia's mother sits glued to the television daily, watching news reports from scientists, and her best friend, Hanna, moves with her Mormon family to Utah for Jesus' return to earth. People cling to normalcy, but the question remains: "IS THE END NEAR?" (p. 15).

In chapters 5-10, the confusion about "the slowing" continues to grow. Days grow longer and the hours of the day no longer make sense: light "unhooked from day, darkness unchained from night" (p. 84). Using the changes experienced during adolescences as a basis, Walker highlights the underlying modern belief that everything, even "the slowing," can be corrected.

This was middle school, the age of miracles, the time when kids shot up three inches over the summer, when breasts bloomed from nothing, when voiced dipped and dove. Our first flaws were emerging, but they were being corrected. Blurry vision could be fixed invisibly with the magic of the contact lens. Crooked teeth were pulled straight with braces. Spotty skin could be chemically cleared. (p. 43)

These chapters also introduce the reader to Julia's school crush, Seth Moreno, and explore the role the government plays in moderating social instability during crisis. The societal disruptions caused by the changing length of day become an issue of global concern. Americans are instructed to adhere to the 24-hour day, a "practical solution" called "clock time" (p. 85). 
It was voluntary, of course. We were not required to squeeze our days into twenty-four little hours. No new law was passed or put into place. This was America. The government could not dictate the way we lived our lives... It was a matter of economic stability, said the politicians, of competitive advantage, and even, some insisted, national security. (p. 85)

The decision to adopt "clock time" was agreed upon by many, not all Americans. Some chose to stay on daylight time, also known as "real time."

Chapters 11-20 explore the social stratification that occurs as people adopt "clock time" versus "real time." As the "real time" drifts farther and farther away from clock time, tensions emerge that rival current racial and class tensions.

The few people who had rejected clock time carried on, living like bean sprouts, reacting to sunlight when it appeared and going dormant whenever our path of earth slipped into the dark. Already, these real-timers seemed very different from us, their customs incompatible with ours. They were widely regarded as freaks. We did not mix. (p. 115).

In fact, several countries around the world make "real time" illegal. To escape persecution, many American real-timers fled the cities to establish colonies in rural areas.

The extended days also seem to be affecting the health of not only animals, but crops and people as well. Julia's mom is one of the first struck by "the syndrome," an illness with wide-ranging symptoms including dizziness, nausea, insomnia, fatigue, and fainting.

In Chapters 21-33 Walker indirectly explores the question, "Who are the dreamers?" All signs point to worsening conditions. People's bodies are not adapting to "the slowing." Days and nights are elongated, the landscape of the earth has begun to change, and weather patterns are no longer predictable. The flora and fauna are dying at an alarming rate. Julia and Seth reconnect as they attempt to save the lives of some beached whales dying along the coast.

We looked for the driest whale, the one most in need. We found it at the edge of the group, and we imagined that it was older than the others. Its skin was striped white with scars. I shooed flies from its eyes, one eye at a time. Seth poured our meager water supply over its head and into its mouth. He petted its side. I felt an urgency like love.

"Hey, kids," someone called from behind us. It was a man in a beach hat, am empty white bucket swinging from one hand. A gust of wind drowned out what he said, so he shouted it again: "That one's already dead." (p. 193)

This event parallels the changing attitudes of the time. People had begun to realize, that the many endeavors to address the problems caused by "the slowing" were useless.

The decline of the Earth is presented in juxtaposition to the developing relationship between Julia and Seth. "We felt better than fine. Sometimes death is proof of life. Sometimes decay points out a certain verve. We were young and we were hungry. We were strong and growing stronger, so healthy we were bursting" (p. 237).

The blossoming love experienced between Julia and Seth is crushed when Seth comes down with the syndrome and is forced by his father to move away to an area with less radiation. Power and communication infrastructures break down, and people lose track of one another. Food stores dwindle, and famine is widespread. People continue to become ill in increasing numbers and die due to the intense heat of the sun. Julia never hears from Seth again. 
The final chapter of the book concludes with Julia's acceptance of her current reality: "We performed all sorts of miracles...And yet, the unknown still outweighed the known. We never determined the cause of the slowing. The source of our suffering remained forever mysterious" (p. 266). Devoid of ideas and resources to stop the slowing, scientists compile the "story of earth," comprised of facts, sounds, and lists, and launch it into space in the hopes that one day other beings will find it. Julia poignantly notes that what is missing from this "story" is "our definitions of love and friendship, our worries, and our dreams, our mercies and our kindnesses and our lies" (p. 267). The book concludes with a powerful reflection on the nature of existence.

But among the artifacts that will never be found - among the objects that will disintegrate long before anyone from elsewhere arrives - is a certain patch of sidewalk on a California street where once, on a dark afternoon in summer at the waning end of the year of the slowing, two kids knelt down together on the cold ground. We dipped our fingers in the wet cement, and we wrote the truest, simplest things we knew, our names, the date, and these words: We were here. (p. 268)

I highly recommend this book for a new student reader program. The narrative uniquely blends a coming of age story, an exploration of human nature, and science. The increasing demand for apocalyptic stories in mainstream media may also make this text a desirable community reader.

Several of the themes addressed provide opportunities for rich discussions with new students and students in transition. For example, the divide between the "real-timers" and the "clock-timers" could provide students with a safe way to begin discussing social stratification, as the book creates a reality in which class and race are no longer the dividing factors. Additionally, the book provides a way to examine the tension between science and religion. What is the role of science in our society? How does religion bind people together or act as a divisive force? This book also opens up a forum to discuss concepts that traverse national borders. Food supply shortages, weather, and health all traverse national borders. How is our world interdependent?

Themes that may be particularly poignant for the new student include the role of familial relationships and the nature of friendships. Both friendships and family bonds undergo intense transformations during the first year of college. Discussing feelings of isolation, loneliness, and instability using Julia's experiences may help students voice emotional challenges that they are facing as they transition. Discussion of these issues can not only help students increase a sense of belonging, but also help instructors and staff identify students that need direct interventions or other support.

The breadth of topics covered in this book could also be used to help new students identify career and academic interests. What aspects of the book were most appealing to them - the science? The relationships? The societal changes? The environmental changes? The changes in the human body? Answers to these questions may help undecided students begin the process of career exploration and tap into their natural curiosity as they pursue a field of study.

The breadth of this book also opens up the door for a variety of collaborations with campus partners. Instructors from a variety of disciplines could incorporate themes into their courses. Psychology instructors could use the text to explore the stages of grief. Sociology courses could use this text as a platform to discuss social stratification, oppression, and segregation. Physics and earth science professors could build content units around the theories and natural forces identified in relation to "the slowing." Courses related to health fields could use "the syndrome" as a way to discuss the diagnostic challenges of illnesses new and old, as well as treatment measures. Courses specializing in government would find ample material for discussion exploring the leadership decisions made by governing bodies throughout the text. Finally, English professors, creative writing instructors, and 
communications instructors alike could use this book as a platform for assignments asking students to tell their own "stories."

It is for the aforementioned reasons that I strongly recommend The Age of Miracles: A Novel. This apocalyptic story is gripping and rich with opportunities for discussion and programming in an academic environment. Walker's debut work would make an excellent addition to the milieu of ideas on any college campus. 